\title{
Peroxisome proliferator-activated receptors and their ligands: nutritional and clinical implications - a review
}

\author{
Bogna Grygiel-Górniak
}

\begin{abstract}
Peroxisome proliferator-activated receptors are expressed in many tissues, including adipocytes, hepatocytes, muscles and endothelial cells; however, the affinity depends on the isoform of PPAR, and different distribution and expression profiles, which ultimately lead to different clinical outcomes. Because they play an important role in lipid and glucose homeostasis, they are called lipid and insulin sensors. Their actions are limited to specific tissue types and thus, reveal a characteristic influence on target cells. PPARa mainly influences fatty acid metabolism and its activation lowers lipid levels, while PPARy is mostly involved in the regulation of the adipogenesis, energy balance, and lipid biosynthesis. PPAR $/ \delta$ participates in fatty acid oxidation, mostly in skeletal and cardiac muscles, but it also regulates blood glucose and cholesterol levels. Many natural and synthetic ligands influence the expression of these receptors. Synthetic ligands are widely used in the treatment of dyslipidemia (e.g. fibrates - PPARa activators) or in diabetes mellitus (e.g. thiazolidinediones - PPARY agonists). New generation drugs - PPARa/y dual agonists - reveal hypolipemic, hypotensive, antiatherogenic, anti-inflammatory and anticoagulant action while the overexpression of PPAR $\beta / \delta$ prevents the development of obesity and reduces lipid accumulation in cardiac cells, even during a high-fat diet. Precise data on the expression and function of natural PPAR agonists on glucose and lipid metabolism are still missing, mostly because the same ligand influences several receptors and a number of reports have provided conflicting results. To date, we know that PPARs have the capability to accommodate and bind a variety of natural and synthetic lipophilic acids, such as essential fatty acids, eicosanoids, phytanic acid and palmitoylethanolamide. A current understanding of the effects of PPARs, their molecular mechanisms and the role of these receptors in nutrition and therapeutic treatment are delineated in this paper.
\end{abstract}

\section{Introduction}

Peroxisome proliferator-activated receptors are ligandactivated transcription factors that regulate genes important in cell differentiation and various metabolic processes, especially lipid and glucose homeostasis. In molecular terms, PPARs represent a family of ligand-activated nuclear hormone receptors (NRs) belonging to the steroid receptor superfamily $[1,2]$ (Figure 1 ). Examples of NRs include the receptors for thyroid hormones, retinoids, 1,25dihydroxy-vitamin D3, steroid hormone receptors and a variety of other ligands. After interaction with the specific ligands, nuclear receptors are translocated to the nucleus,

Correspondence: bgrygiel@ump.edu.pl

Department of Bromatology and Human Nutrition, University of Medical Sciences, Poznan, Poland where they change their structure and regulate gene transcription [3-5].

\section{PPAR structure and function}

The three-dimensional structure of PPARs consists of a DNA binding domain in the $\mathrm{N}$-terminus and a ligand binding domain (LBD) in the C-terminus. After interaction with agonists, PPARs are translocated to the nucleus and heterodimerize with another nuclear receptor - the retinoid X receptor (RXR) (Figure 2). The RXR forms a heterodimer with a number of other receptors (e.g., vitamin D or thyroid hormones). The specific DNA regions of target genes that bind with PPARs are termed peroxisome proliferator hormone response elements (PPREs) [1]. The PPREs are found in the promoters of PPAR responsive genes, such as the fatty acid-binding 


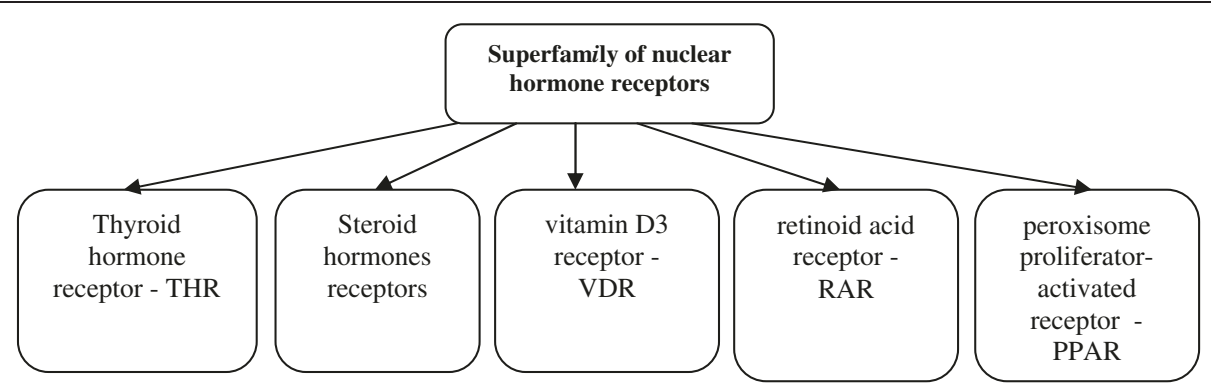

Figure 1 Superfamily of nuclear hormone receptors.

protein (aP2) [5]. In most cases, this process activates transcription of various genes involved in diverse physiological and pathophysiological processes.

The function of PPARs is modified by a number of coactivators and corepressors, the presence of which can either stimulate or inhibit receptor function, respectively [6]. Ligands that activate PPAR $\gamma$-RXR cause an exchange of co-repressors for co-activators [7,8]. Human cells are characterized by a different availability of cofactors that depends on the type of cell and the association of specific cofactors to other genes $[7,9,10]$.

\section{Types of PPARs and their tissue expression}

The family of peroxisome proliferation-activated receptors comprises three isoforms: PPAR $\alpha, \operatorname{PPAR} \beta / \delta$ and PPARY [1]. These three isotypes differ from each other in terms of their tissue distributions, ligand specificities and physiological roles. Each of them either activates or suppresses different genes with only partial overlap in activity (Figure 3) [5]. All isoforms participate in lipid homeostasis and glucose regulation (energy balance), and, until recently, their actions were thought to be limited to specific tissue types (Figure 4) [5,11]. PPAR $\alpha$ is highly expressed in metabolically active tissues, such as liver, heart, skeletal muscle, intestinal mucosa and brown adipose tissue. This receptor is implicated in fatty acid metabolism and its activation lowers lipid levels [12-15].

PPARY is expressed in white and brown adipose tissue, the large intestine and spleen. However, its expression is highest in adipocytes and it plays a key role in the regulation of adipogenesis, energy balance, and lipid biosynthesis [14,16-18]. This receptor also participates in lipoprotein metabolism and insulin sensitivity.

The least known isoform is $\operatorname{PPAR} \beta / \delta$, which has not been so intensely studied as PPAR $\alpha$ and PPAR $\gamma$. PPAR $\beta / \delta$ is expressed ubiquitously in virtually all tissues; however, it is particularly abundant in the liver, intestine, kidney, abdominal adipose tissue, and skeletal muscle, all of which are involved in lipid metabolism. It participates in fatty acid oxidation, mainly in skeletal and cardiac muscles, regulates blood cholesterol concentrations and glucose levels $[1,13,19,20]$.

In conclusion, PPAR $\alpha$ and PPAR $\beta / \delta$ mainly facilitate energy combustion, whereas PPAR $\gamma$ contributes to energy storage by enhancing adipogenesis [21].

\section{PPAR ligands}

Many natural and synthetic agonists of PPARs are used in the treatment of glucose and lipid disorders. PPARs perform different activities, mainly via endogenous ligands produced in the metabolic pathways of fatty acids; and therefore, they are called lipid sensors. PPAR agonists have different properties and specificities for individual PPAR receptors, different absorption/distribution profiles, and distinctive gene expression profiles, which ultimately lead to different clinical outcomes $[1,5,17,22,23]$.

The characteristic feature of the PPAR ligand binding cavity is its size, which is $3-4$ times larger than that of the other nuclear receptors. Thus, PPARs have the capability to accommodate and bind a variety of natural and synthetic lipophilic acids, such as essential fatty acids (EFA) (Figure 5). These acids act as PPAR agonists that transcript the genes involved in glucose and lipid

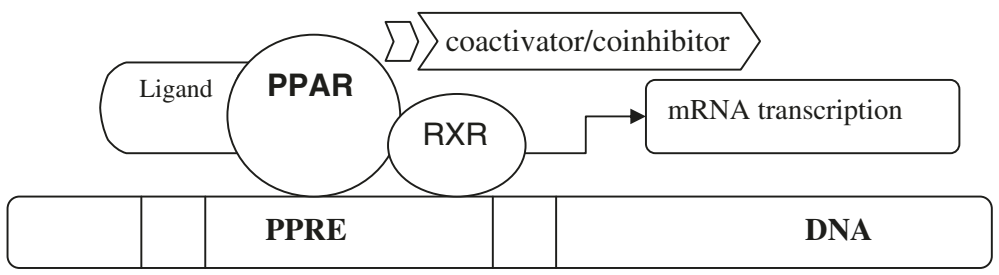

Figure 2 Mechanism of gene transcription by PPARs. 


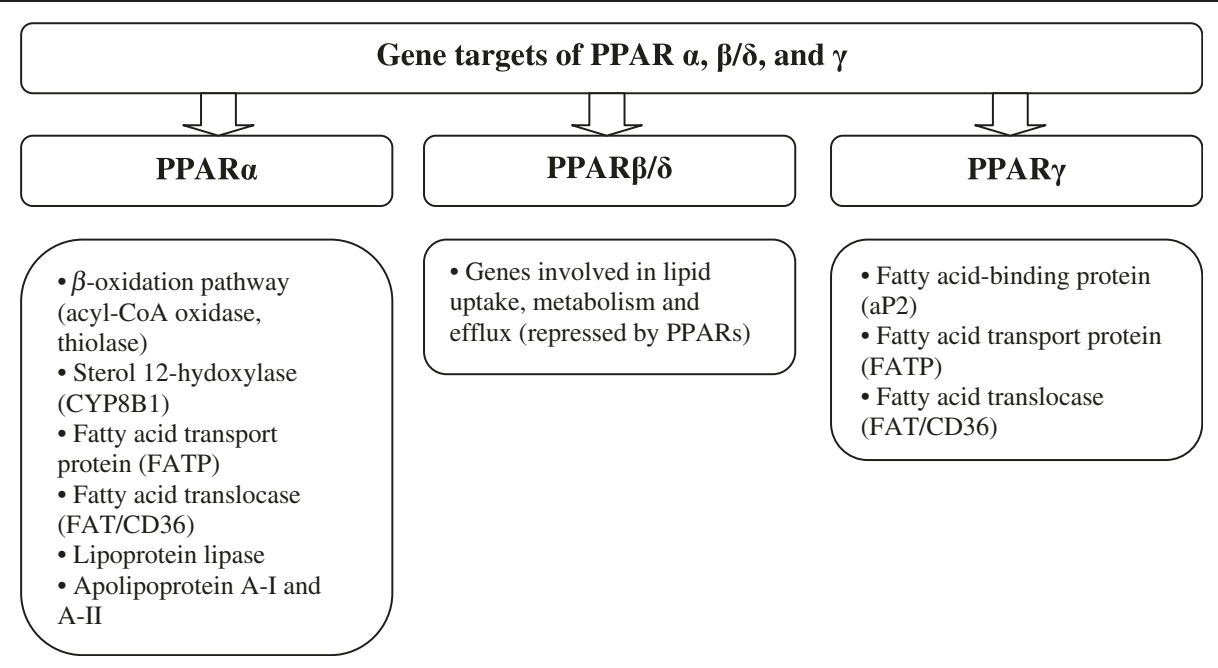

Figure 3 PPARs and their gene targets.

homeostasis [12,22,24]. They include docosahexaenoic acid and eicosapentaenoic acid used in the prevention and treatment of cardiovascular and metabolic diseases [25]. Not only EFA but also eicosanoids are natural ligands of PPARs - e.g. leukotriene $\mathrm{B}_{4}$ stimulates PPAR $\alpha$, and prostaglandin $\mathrm{PGJ}_{2}$ activates PPARY [22]. However, both EFA and eicosanoids are required in relatively high concentrations (approximately $100 \mu \mathrm{M}$ ) for PPAR activation [24]. Also, synthetic ligands are widely used in clinical practice - for example, fibrates (PPAR $\alpha$ ligands) are recommended in the dyslipidemic state (hypertriglyceridemia) and thiazolidinediones (PPAR $\gamma$ agonists) are used in the treatment of diabetes mellitus [26-29].

\section{Functional role of PPARa}

As mentioned above, PPAR $\alpha$ is expressed mainly in tissues with a high capacity for fatty acid oxidation, e.g. the liver, heart, and skeletal muscle. It also plays a role in glucose homeostasis and insulin resistance development (Figure 6) [29]. Natural or pharmacological ligands (fatty acids and fibrates, respectively) primarily control the expression of genes involved in lipid metabolism. If the concentration of fatty acids increases, PPAR $\alpha$ is activated and uptakes oxidized forms of these acids [30,31]. Oxidation of fatty acids is mainly present in the liver and it prevents steatosis in the case of starvation/fasting. During the influx of fatty acids, transcription of PPAR $\alpha$ regulated genes is stimulated and the oxidation systems (microsomal omega-oxidation system, and mitochondrial and peroxisomal beta-oxidation) are activated (Figure 7) $[21,32]$. This activation and increased PPAR $\alpha$ sensing in the liver result in increased energy burning and reduced fat storage. Conversely, ineffective PPAR $\alpha$ sensing or decreased fatty acid oxidation causes a reduction in energy burning that results in hepatic steatosis and steatohepatitis (especially during overnight or prolonged fasting)

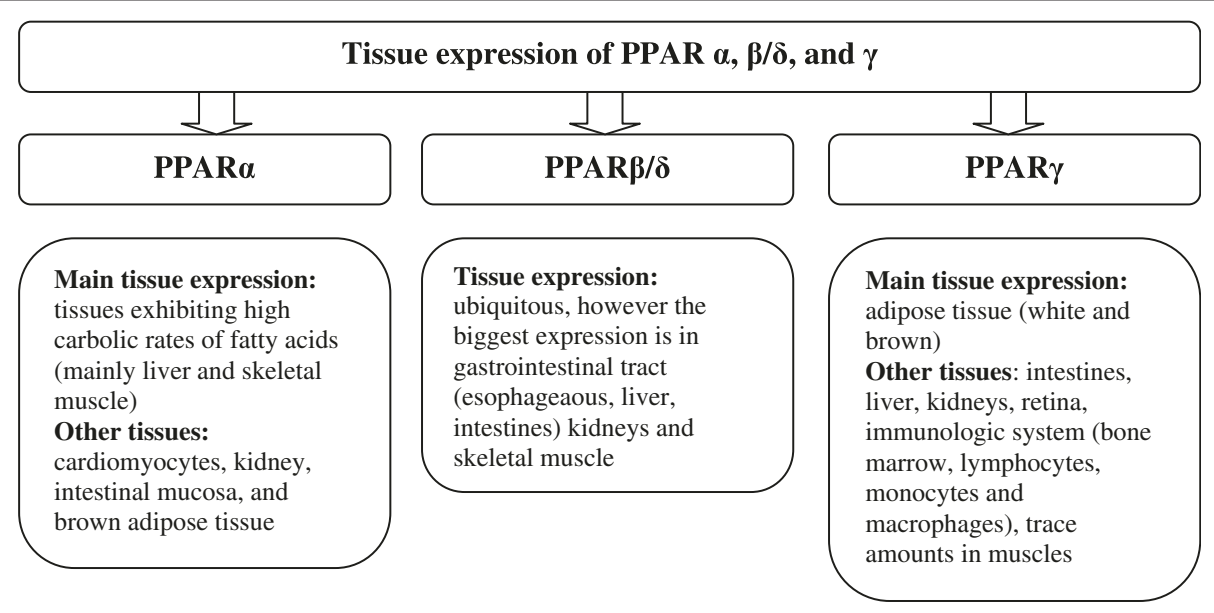

Figure 4 Expression of PPARs in specific tissues. 


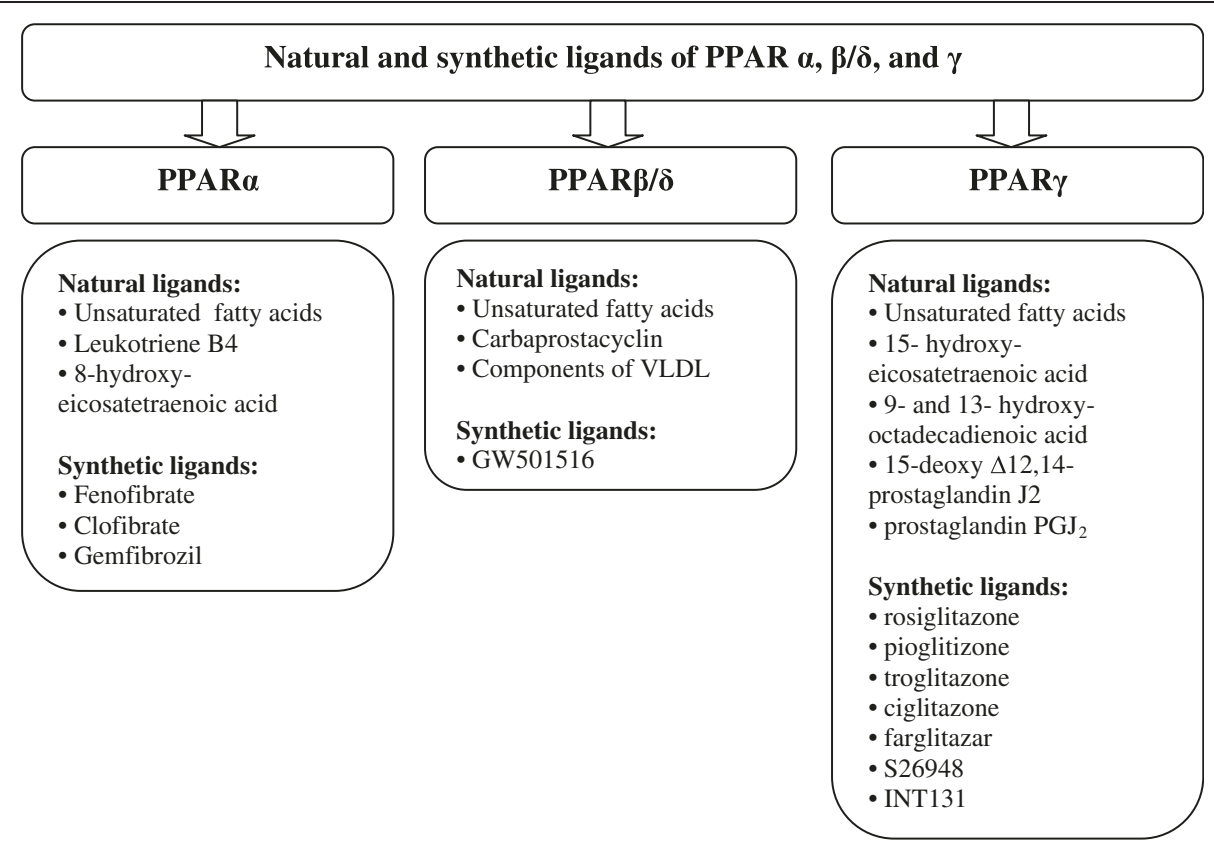

Figure 5 Natural and synthetic ligands of PPAR.

[32,33]. The diminished effectiveness of oxidation systems is caused by genetic or toxic factors (including drug related ones), and metabolic disturbances. In animal models, inefficient PPAR $\alpha$ sensing (characteristic for

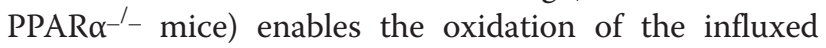
fatty acids and leads to severe hepatic steatosis development. Administration of PPAR $\alpha$ agonists prevents these processes and even reverses hepatic fibrosis (in animal models) [34]. Thus, PPAR $\alpha$ functions as a lipid sensor and it controls energy combustion. It also plays also a prominent role in the pathogenesis of fatty liver disease (FLD) and ligands of this receptor might be effective in the reduction of hepatic staetosis by increasing energy utilization $[32,33]$.

\section{Natural agonists of PPARa}

The natural ligands of PPAR $\alpha$ are omega- 3 fatty acids. These acids contain three essential elements for optimal

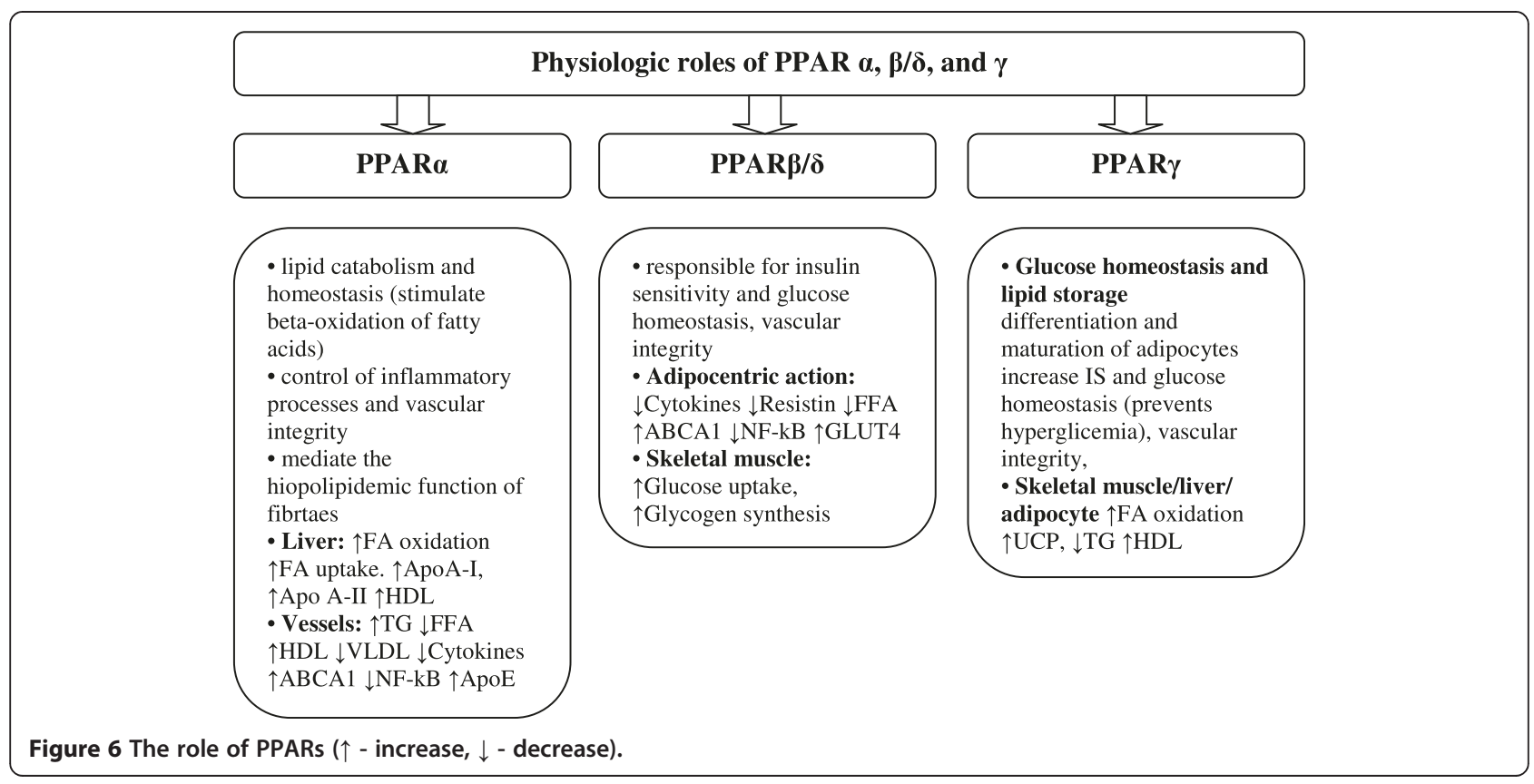




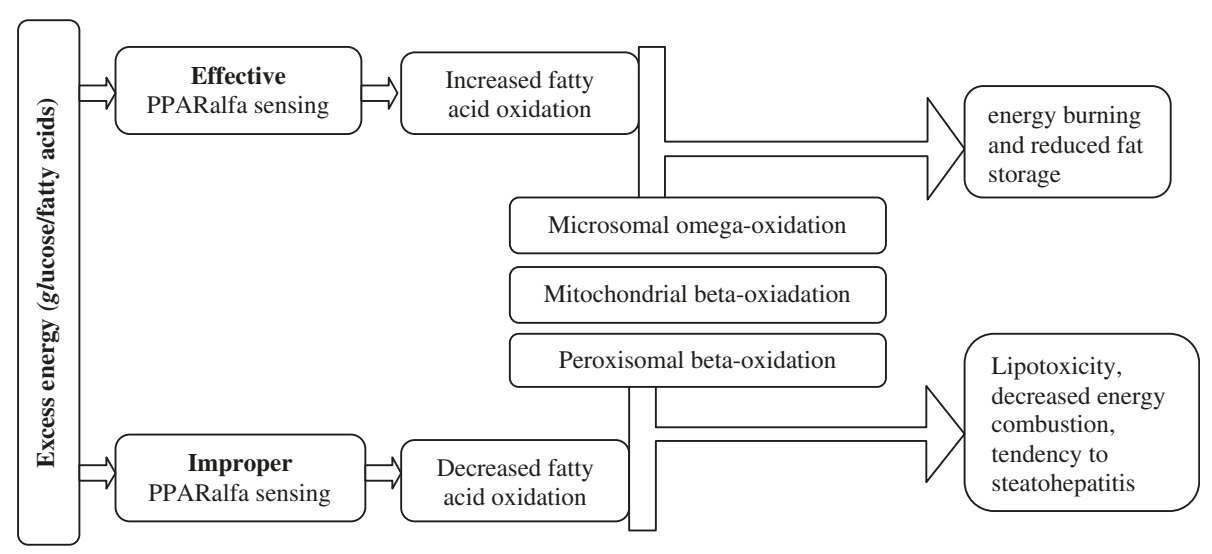

Figure 7 Consequence of PPARa activation.

binding: a polar head group (a carboxylic group in the molecule of docosahexaenoic acid - DHA and eicosapentaenoic acid - EPA), a linker region (their long chains), and a hydrophobic tail [16]. Because omega-3 fatty acids are highly polyunsaturated, they readily undergo oxidation and stimulate PPARs. Sethi et al. proved that not only native EPA but also oxidized EPA modestly activates PPAR $\alpha$. Moreover, oxidized EPA, much more than native EPA, stimulates this receptor in endothelial cells. Therefore, it is suspected that oxidation of the omega- 3 fatty acids converts them into a stronger PPAR $\alpha$ agonist [30]. Similarly, oxidation of LDL transforms them into potent stimulators of PPAR $\alpha$ in endothelial cells [31]. Thus, the possibility of lipid oxidation may be one of the first steps involved in the generation of efficient PPAR $\alpha$ agonists.

In addition to PPAR activation, EPA and DHA have many beneficial health effects which are not characteristic for PPAR ligands. They reduce the risk of coronary heart disease, hypertension, primary heart attack, rheumatoid arthritis and play an important role in the development of attention-deficit/hyperactivity disorder [25]. These beneficial effects are not observed with other typical PPARs ligands; however, EPA and DHA do not show a number of PPAR effects, such as decreasing insulin resistance, that probably occur due to dissociation between $n-3$ polyunsaturated fatty acids and lipid metabolism in the hyperglycemic state [35].

Omega-3 fatty acids also reveal an anti-inflammatory effect that results from the inhibition of their own oxidation caused by activated NF- $\mathrm{KB}$ in a PPAR $\alpha$-dependent pathway $[14,16]$. In addition, PPAR $\alpha$ mediates the antiinflammatory actions of palmitoylethanolamide, the naturally occurring amide of palmitic acid and ethanolamine [15].

\section{Synthetic agonists of PPARa}

Synthetic PPAR $\alpha$ ligands such as fibrates (e.g. clofibrate, fenofibrate, and bezafibrate) decrease the triglyceride-rich lipoproteins in serum through an increase in the gene expression involved in fatty acid- $\beta$-oxidation and a decrease in apolipoprotein C-III gene expression [26,29]. They are widely used in the pharmacological treatment of hypertriglyceridemia. After activation by fibrates, PPAR $\alpha$ receptors connect with the 9-cis retinoic acid receptor and then bind to peroxisome proliferator response elements. Fibrates not only reveal a triglyceride-lowering effect, but also increase HDL cholesterol (partly by increasing apolipoprotein A-I and A-II gene expression). Their activity results in decreasing systemic availability of fatty acids and a lowering of fatty acid uptake in muscles. They also increase insulin sensitization and reduce plasma glucose levels $[12,26,29]$. In consequence, they may slow arteriosclerosis progression and reduce cardiovascular events [36]. However, two large-scale studies into fibrates (the FIELDstudy and the ACCORDlipid arm) in patients with diabetes did not show any reduction in fatal cardiovascular incidences or non-fatal myocardial infarction and stroke compared with simvastatin alone [37,38]. It must also be underlined that fibrate intake may cause an increase in serum creatinine levels (via a decrease in tubular secretion, reduced clearance and possibly increased production of creatinine) [39-41]. However, long-term studies have shown a slowing of the decline in renal function [37-39].

Active metabolites of fibrates, such as clofibric acid and fenofibric acid, are dual activators of PPAR $\alpha$ and PPAR $\gamma$, with about a 10 -fold selectivity for PPAR $\gamma$. The effect of bezafibrate, another compound from this group, is wider because it activates all 3 PPAR subtypes $(\alpha, \gamma$ and $\delta)$ at comparable doses to other fibrates $[1,5]$. Therefore, bezafibrate is considered a panagonist for all 3 PPAR isoforms with the potential to directly improve insulin sensitization via PPAR $\gamma$ activation.

\section{Functional role of PPAR $\beta / \delta$}

PPAR $\beta / \delta$ (referred to also as PPAR $\delta$, PPAR $\beta$, hNUC1 or FAAR) plays a key role in lipid and cholesterol metabolism. 
It is implicated in fatty acid oxidation, improving lipid profiles and reducing adiposity, which in consequence prevents obesity development $[19,42]$. In animals, PPAR $\beta /$ $\delta$ serves as a regulator of fat consumption. PPAR $\beta / \delta$ deficient mice challenged with a high-fat diet showed reduced energy uncoupling and were prone to obesity, whereas PPAR $\beta / \delta$ activation led to resistance to nutritionally (induced by high-fat diet) or genetically triggered obesity (in genetically modified mice) [19].

Decreased PPAR $\beta / \delta$ expression is also observed in cardiac muscle during the hyperglycemic state in diabetes mellitus $[43,44]$. Conversely, overexpression of this receptor in cardiac cells diminishes lipid accumulation in the presence of a high fat diet, and increases glucose metabolism. In consequence, the heart is protected against ischemia-reperfusion injury, suggesting that activation of this receptor might be useful in diabetic cardiomyopathy [45].

Also beneficial is $\operatorname{PPAR} \beta / \delta$ activation in adipocytes and skeletal muscles that results in fatty acid oxidation and utilization (studies in vitro) [19]. Thus, PPAR $\beta / \delta$ might be considered a potential target in the treatment of obesity and obesity related disorders. This receptor is also a mediator of embryo implantation and cancer development $[42,46]$. Its high expression in the large intestine has been implicated in the development of colon cancer $[11,47]$. In this process, PPAR $\beta / \delta$ was stimulated by arachidonic acid, which resulted in the upregulation of cyclooxygenase (COX)-2 and the overproduction of prostaglandin (PG)E2 - an activator of colon cancer cells. Similarly, activation of $\operatorname{PPAR} \beta / \delta$ also stimulated the cell line proliferation of human breast and prostate cancer [20].

\section{Agonists of PPAR $\beta / \delta$}

Dual agonists of PPAR $\beta / \delta$ improve insulin sensitivity in both murine models and in humans. Thus, they might be considered a potential target in the treatment of obesity and obesity associated disorders. Only bezafibrate, a traditional PPAR $\alpha$ agonist, seems to be a safe pan-agonist for all PPAR isotypes, but it has relatively low potency and low affinity for PPAR $\beta / \delta$ [48].

\section{Clinical and nutritional role of PPARY}

PPAR $\gamma$ has attracted significant scientific and clinical interest because of its role in macronutrient metabolism. It is a target of the synthetic insulin sensitizers - thiazolidinediones - used in the treatment of type 2 diabetes mellitus. This receptor is abundantly expressed in adipose tissue where it plays a central role in adipogenesis and appears to be primarily involved in the regulation of lipid metabolism. Because the PPAR $\gamma$ gene has separate promoters and 5 exons, it results in three mRNAs: PPAR $\gamma 1$, PPAR $\gamma 2$, and PPAR 3 . Proteins produced from
PPAR 1 and PPAR 3 mRNAs are identical, whereas the product of PPAR $\gamma 2$ contains an additional $\mathrm{NH}_{2}$-terminal region composed of 30 amino acids. All PPAR $\gamma$ isoforms play an important role in adipocyte differentiation and glucose metabolism; however, their expression is different. The PPAR 1 isoform is expressed in nearly all cells, while PPAR 2 is limited mainly to adipose tissue. Nevertheless, PPAR $\gamma 2$ is a more potent transcription activator [8].

Both forms of PPAR 1 and PPAR 2 are essential for the development of adipose tissue and the control of insulin sensitivity. However, PPAR 2 is the isoform regulated in response to nutrient intake and obesity $[9,10]$. The study of Medina-Gomez et al. based on an animal model proved that removing PPAR $\gamma 2$ from genetically obese POKO mice decreases the fat accumulation in adipocytes compared to normal obese mice on the same diet. This study showed that the PPAR 2 isoform prevents lipotoxicity in different mechanisms including promotion of adipose tissue expansion, the augmentation of lipid-buffering capacity in peripheral organs (liver, muscle, and beta cells of pancreas), and the proliferative response of $\beta$-cells to insulin resistance [18].

Adipose PPAR $\gamma$ protects non-adipose tissues against excessive lipid overload and maintains normal organ function (liver, skeletal muscle). Activated PPAR $\gamma$ in adipocytes guarantees a balanced and adequate secretion of adipocytokines (adiponectin and leptin) that are mediators of insulin action in peripheral tissues. In consequence, the insulin sensitivity of the whole body is maintained [49]. Apart from this adipogenetic activity, PPAR $\gamma$ is also important in lipid metabolism, and it regulates the genes participating in the release, transport, and storage of fatty acids such as lipoprotein lipase (LPL) and the fatty acid transporter CD36 $[9,17,18]$. PPAR $\gamma$ is the potent function modulator not only found in adipose tissue but also in endothelial cells and vascular smooth muscle cells. In endothelial cells it regulates targets relevant to inflammation and atherosclerosis [50].

Despite controlling lipid metabolism, PPAR $\gamma$ also participates in the regulation of cancer development. Their agonists inhibit or promote cancer growth depending on cellular conditions and the stimulated signaling pathway (anti-proliferative and apoptotic) [8,31]. They influence tumor-associated macrophages and tumor vasculature and significantly attenuate tumor progression [23]. These data suggested that PPAR $\gamma$ ligands may become new convenient therapeutic modifiers targeting simultaneously tumors and their microenvironment [51].

\section{Natural agonists of PPARY}

The selective PPAR $\gamma$ modulators are often called SPARMs by analogy to selective estrogen receptor modulators 
(SERMs). The distinct actions of SPARMs depend on the cellular context and on different receptor conformations, resulting in diverse gene interactions [52].

Selected fatty acids are considered natural modulators of PPAR $\gamma$; however, their connection with the receptor does not always lead to PPAR activation and target gene transcription. Activation of PPAR $\gamma$ by natural ligands such as PUFAs (mainly docosahexaenoic acid and eicosapentaenoic acid) results in a functional response in the tumor cells. Many studies have provided evidence that DHA inhibits the tumor development through activation of PPARY (e.g. the growth of human lung cancer cells) [53]. If DHA is delivered to breast cancer cells by albumin or by enriched LDL with n-3 PUFAs, it inhibits the proliferation of these cells and stimulates their apoptosis [54-56]. Syndecan-1 (the heparan sulfate proteoglycan) - the activating factor of apoptosis - participates in this process. After the stimulation of PPARY by DHA, the transcriptional upregulation of the syndecan-1 target gene is present [56]. In animal studies long-chain monounsaturated fatty acids (LC-MUFAs) with chain lengths longer than 18 (i.e., C20:1 and C22:1 isomers combined) may ameliorate obesity-related metabolic dysfunction through increased expression of PPAR $\gamma$ and decreased inflammatory marker expression in white adipose tissue [57]. In in vitro studies, activation of PPAR $\alpha$ and PPAR $\beta / \delta$ in human cell lines of breast cancer stimulated cell proliferation [58,59], whereas ligands for PPAR $\gamma$ inhibited this process [20].

Apart from polyunsaturated fatty acids, phytanic acid is also a natural PPAR $\gamma$ agonist in the human diet that reveals a similar activity to omega-3 PUFA and increases glucose uptake and insulin sensitivity; however, with less capacity to differentiate adipocytes [60].

\section{PPAR $\gamma$ pharmacological agonists}

PPARY is a regulator of lipid and glucose metabolism and therefore its synthetic ligands such as glitazones the derivatives of thiazolidinediones (e.g., troglitazone, rosiglitazone and pioglitazone) - improve insulin and glucose parameters and increase whole body insulin sensitivity. Therefore, they are called insulin-sensitizing medications used in the treatment of diabetes [61]. They indirectly increase insulin-stimulated glucose uptake in adipocytes, hepatocytes and skeletal muscle cells $[62,63]$. The effects of pharmacological PPAR $\gamma$ activation by thiazolidinediones have been attributed, at least in part, to decreased free fatty acid (FFA) levels and increased lipid storage in adipose tissue, in which it is most highly expressed. In consequence, lipotoxicity in the muscles and liver is reduced. PPAR $\gamma$ agonists also have the ability to redistribute fat from visceral to subcutaneous depots and increase adiponectin and reduce tissue necrosis factors $[63,64]$. Moreover, rosiglitazone and pioglitazone are used in the treatment of patients with type 2 diabetes because they decrease hepatic glucose production and prolong pancreatic $\beta$-cell function by preventing apoptosis of $\beta$-cells $[62,63]$. They reduce fasting plasma glucose and glycated hemoglobin A1c (pioglitazone 15-45 mg/day, rosiglitazone $2-6 \mathrm{mg} / \mathrm{twice}$ a day) [65-67]. However, the influence of both thiazolidinediones on cardiovascular outcomes in patients with diabetes mellitus is different. The positive effect of pioglitazone was demonstrated in a PROactive study revealing 16\% reduced cardiovascular complications in the main secondary endpoint (a composite of all-cause-mortality, non-fatal myocardial infarction and stroke) compared with placebo treatment [68]. Conversely, rosiglitazone was associated with significant increases in myocardial infarction and death from cardiovascular causes after only relatively short-term exposure [69] and the European Medicines Agency withdrew approval of this medication in 2010 due to these cardiovascular safety concerns [64]. The differences between thiazolidinediones are probably caused by their diverse effects on lipid sub-fractions [63]. Pioglitazone increases HDL cholesterol and decreases triglycerides and fasting plasma free fatty acids (without any influence on total cholesterol and LDL cholesterol) [64,70,71]. Rosiglitazone significantly augments HDL levels [64,70,71], total cholesterol and the LDL fraction [71].

In diabetes mellitus, long-term activation of PPAR $\gamma$ by thiazolidinediones not only reduces glycaemia and insulinemia but also attenuates vascular dysfunction [72] PPARy is expressed in vessels, specifically in vascular smooth muscle cells and endothelium. Recent studies suggest that activators of PPAR $\gamma$ not only modify metabolic disturbances but also protect vascular function in diabetes [72]. Using an animal model, Bagi et al. proved that short-term treatment of type 2 diabetic mice with rosiglitazone augmented NO-mediated flow-dependent dilations of coronary arterioles by reducing vascular superoxide production via a favorable alteration of oxidant/antioxidant enzyme activities [73]. PPAR $\gamma$ agonists also lower blood pressure and decrease circulating PAI-1 and CRP levels in patients with diabetes $[27,28]$.

Apart from these positive effects, activation of PPAR $\gamma$ by glitazones attenuates systemic inflammation $[3,4]$ and reduces tumor growth and angiogenesis. PPAR $\gamma$ activation by agonist RS5444 may inhibit anaplastic thyroid cancer growth [74]. Only troglitazone revealed tumorpromoting and pro-angiogenic properties - it promoted hepatic carcinogenesis and liposarcomas, and thus this agonist was rejected from the treatment $[72,75]$.

Despite many beneficial features of glitazones (metabolic and anti-arteriosclerotic activity), they also exhibit side effects, such as weight gain, edema, bone fractures, heart failure and increased risk of myocardial infarctions, which have limited the use of these drugs in diabetic 
patients with high lipid levels [76]. Fortunately, new selective PPAR $\gamma$ modulators are currently in development (such as S26948 [77] and INT131 [78]) and these should stimulate glucose metabolic pathways and minimize the side effects of full PPAR- $\gamma$ agonists.

\section{PPARa/ $Y$ dual agonists}

The synthesis of new drug generation - PPAR $\alpha / \gamma$ dual agonists - connecting positive influences on both lipid and glucose metabolism has been recently developed as a response to the treatment challenge of co-existing type 2 diabetes mellitus with dyslipidemia. These double agonists not only have anti-diabetic capacity but also reduce arteriosclerosis development. They also exhibit anti-inflammatory and anticoagulant action, improve endothelial function, decrease plasma free fatty acids and lower blood pressure revealing beneficial effects on the vasculature. However, recent studies show that PPAR $\alpha / \gamma$ dual agonists, similar to glitazones, exhibit the same side effects; for example, weight gain and edema [48,79]. None of them may be safely used in clinical treatment because of the increased risk of bladder cancer and hyperplasia (ragaglitazar and naveglitazar) or [80], renal dysfunction (tesaglitazar) [81] and increased cardiovascular risk (muraglitazar) [82]. A recent study (currently in phase III trials) of aleglitazar decreased $\mathrm{HbA1c}$ and revealed beneficial effects on lipid profiles reducing triglyceride and LDL, and increasing HDL cholesterol. It changes the atherogenic small dense LDL particles into larger LDL molecules [108] and in consequence reduces inflammatory/cardiovascular risk [83]. This thiazolidinedione with a balanced affinity for both $\alpha$ and $\gamma$ receptor subtypes is very promising; however, further studies are needed.

\section{Conclusions}

Considering the wide range of actions on glucose, lipid metabolism and cell proliferation/apoptosis, PPARs and their modulators are suggested for the treatment of metabolic disorders such as hyperglycaemia, dyslipidemia and atherosclerosis. The prevention and treatment of both lipid and glucose profile disorders should consider the potency and affinity of selective PPARs and their potential cancerogenic influences. Therefore, natural compounds and their close derivatives are being targeted as future drugs against metabolic diseases. Even though early preclinical data are very promising, it is necessary to evaluate the clinical properties of new PPAR agonists and their influence on patient health.

\section{Competing interests}

The author declares that he has no competing interests.

\section{Acknowledgments}

This work was supported by the Polish National Science Centre (NSC) under the Grant No. N404 504638.
Received: 8 October 2013 Accepted: 7 February 2014

Published: 14 February 2014

\section{References}

1. Berger J, Moller DE: The mechanisms of action of PPARs. Annu Rev Med 2002, 53:409-435.

2. Boitier $\mathrm{E}$, Gautier JC, Roberts R: Advances in understanding the regulation of apoptosis and mitosis by peroxisome-proliferator activated receptors in pre-clinical models: relevance for human health and disease. Comp Hepatol 2003, 2(1):3.

3. Rogue A, Lambert C, Jossé R, Antherieu S, Spire C, Claude N, Guillouzo A: Comparative gene expression profiles induced by PPARY and PPARa/ $/ \gamma$ agonists in human hepatocytes. PLoS One 2011, 6(4):e18816.

4. Rogue A, Spire C, Brun M, Claude N, Guillouzo A: Gene expression changes induced by PPAR gamma agonists in animal and human liver. PPAR Res 2010, 2010:325183.

5. Willson TM, Brown PJ, Sternbach DD, Henke BR: The PPARs: from orphan receptors to drug discovery. J Med Chem 2000, 43:527-550.

6. Viswakarma N, Jia Y, Bai L, Vluggens A, Borensztajn J, XU J, Reddy JK: Coactivators in PPAR-regulated gene expression. PPAR Res 2010, 2010:2050126.

7. Heikkinen S, Auwerx J, Argmann CA: PPARy in human and mouse physiology. Biochim Biophys Acta 2007, 1771(8):999-1013.

8. Feige JN, Gelman L, Michalik L, Desvergne B, Wahli W: From molecular action to physiological outputs:peroxisome proliferator-activated receptors are nuclearreceptors at the crossroads of key cellular functions. Prog Lipid Res 2006, 45(2):120-159.

9. Ren D, Collingwood TN, Rebar EJ, Wolffe AP, Camp HS: PPARgamma knockdown by engineered transcription factors: exogenous PPARgamma2 but not PPARgamma1 reactivates adipogenesis. Genes Dev 2002, 16(1):27-32.

10. Werman A, Hollenberg A, Solanes G, Bjorbaek C, Vidal-Puig AJ, Flier JS: Ligand-independent activation domain in the $\mathrm{N}$ terminus of peroxisome proliferator-activated receptor gamma (PPARgamma). Differential activity of PPARgamma1 and -2 isoforms and influence of insulin. J Biol Chem 1997, 272(32):20230-20235.

11. Sertznig P, Seifert M, Tilgen W, Reichrath J: Present concepts and future outlook: function of peroxisome proliferator-activated receptors (PPARs) for pathogenesis, progression, and therapy of cancer. J Cell Physiol 2007, 212(1):1-12

12. Neschen S, Morino K, Dong J, Wang-Fischer Y, Cline GW, Romanelli AJ, Rossbacher JC, Moore IK, Regittnig W, Munoz DS, Kim JH, Shulman GI: $\mathrm{n}-3$ Fatty acids preserve insulin sensitivity in vivo in a peroxisome proliferator-activated receptor-alpha-dependent manner. Diabetes 2007, 56(4):1034-1041.

13. Delerive P, Furman C, Teissier E, Fruchart J, Duriez P, Staels B: Oxidized phospholipids activate PPARalpha in a phospholipase A2-dependent manner. FEBS Lett 2000, 471(1):34-38.

14. Kliewer SA, Sundseth SS, Jones SA, Brown PJ, Wisely GB, Koble CS, Devchand P, Whali W, Willson TM, Lenhard JM, Lehmann JM: Fatty acids and eicosanoids regulate gene expression through direct interactions with peroxisome proliferator- activated receptors alpha and gamma. Proc Natl Acad Sci U S A 1997, 94(9):4318-4323.

15. Lo Verme J, Fu J, Astarita G, La Rana G, Russo R, Calignano A, Piomelli D: The nuclear receptor peroxisome proliferator-activated receptor-alpha mediates the anti-inflammatory actions of palmitoylethanolamide. Mol Pharmacol 2005, 67(1):15-19.

16. Sheu SH, Kaya T, Waxman DJ, Vajda S: Exploring the binding site structure of the PPAR gamma ligand-binding domain by computational solvent mapping. Biochemistry (Mosc) 2005, 44(4):1193-1209.

17. Lehrke M, Lazar MA: The many faces of PPARgamma. Cell 2005, 123(6):993-999.

18. Medina-Gomez G, Gray SL, Yetukuri L, Shimomura K, Virtue S, Campbell M, Curtis RK, Jimenez-Linan M, Blount M, Yeo GSH, Lopez M, Seppänen-Laakso T, Ashcroft FM, Orešič M, Vidal-Puig A: PPAR gamma 2 prevents lipotoxicity by controlling adipose tissue expandability and peripheral lipid metabolism. PLoS Genet 2007, 3(4):e64.

19. Wang YX, Lee CH, Tiep S, Yu RT, Ham J, Kang H, Evans RM: Peroxisomeproliferator-activated receptor delta activates fat metabolism to prevent obesity. Cell 2003, 113(2):159-170.

20. Stephen RL, Gustafsson MC, Jarvis M, Tatoud R, Marshall BR, Knight D, Ehrenborg E, Harris AL, Wolf CR, Palmer CN: Activation of peroxisome 
proliferator-activated receptor delta stimulates the proliferation of human breast and prostate cancer cell lines. Cancer Res 2004 64(9):3162-3170

21. Rao MS, Kashireddy P, Musunuri S, Okonkwo A: Prevention/reversal of choline deficiency-induced steatohepatitis by a peroxisomeproliferatoractivated receptor alpha ligand in rats. In Vivo 2002, 16(2):145-152.

22. Krey G, Braissant O, L'Horset F, Kalkhoven E, Perroud M, Parker MG, Wahli W: Fatty acids, eicosanoids, and hypolipidemic agents identified as ligands of peroxisome proliferator-activated receptors by coactivator-dependent receptor ligand assay. Mol Endocrinol 1997, 11(6):779-791.

23. Margeli A, Kouraklis G, Theocharis S: Peroxisome proliferator activated receptor-gamma (PPAR-gamma) ligands and angiogenesis. Angiogenesis 2003, 6(3):165-169.

24. Plutzky J: Peroxisome proliferator-activated receptors in vascular biology and atherosclerosis: emerging insights for evolving paradigms. Curr Atheroscler Rep 2000, 2(4):327-335.

25. Bang JO, Dyberg J: Fish oil consumption and mortality from coronary heart disease. N Engl J Med 1985, 313:822-823.

26. Taniguchi A, Fukushima M, Sakai M, Tokuyama K, Nagata I, Fukunaga A, Kishimoto H, Doi K, Yamashita Y, Matsuura T, Kitatani N, Okumura T, Nagasaka S, Nakaishi S, Nakai Y: Effects of bezafibrate on insulin sensitivity and insulin secretion in non-obese Japanese type 2 diabetic patients. Metabolism 2001, 50(4):477-480.

27. Bakris GL, Dole JF, Porter LE, Huang C, Freed MI: Rosiglitazone improves blood pressure in patients with type 2 diabetes mellitus. Diabetes 2000, 49(suppl 1):A96.

28. Nakamura T, Ushiyama C, Shimada N, Hayashi K, Ebihara I, Koide H: Comparative effects of pioglitazone, glibenclamide, and voglibose on urinary endothelin-1 and albumin excretion in diabetes patients. J Diabetes Complications 2000, 14(5):250-254.

29. Fruchart JC, Staels B, Duriez P: The role of fibric acids in atherosclerosis. Curr Atheroscler Rep 2001, 3(1):83-92.

30. Volker D, Fitzgerald P, Major G, Garg M: Efficacy of fish oil concentrate in the treatment of rheumatoid arthritis. J Rheumatol 2000, 27(10):2343-2346.

31. Sethi S, Ziouzenkova O, Ni H, Wagner DD, Plutzky J, Mayadas TN: Oxidized omega-3 fatty acids in fish oil inhibit leukocyte-endothelial interactions through activation of PPAR alfa. Blood 2002, 100(4):1340-1346.

32. Rao MS, Reddy JK: PPAR alpha in the pathogenesis of fatty liver disease. Hepatology 2004, 40(4):783-786.

33. Schwimmer JB, Behling C, Newbury R, Deutsch R, Nievergelt C, Schork NJ, Lavine JE: Histopathology of pediatric nonalcoholic fatty liver disease. Hepatology 2005, 42(3):641-649.

34. Ip E, Farrell GC, Robertson G, Hall P, Kirsch R, Leclercq I: Central role of PPARalpha-dependent hepatic lipid turnover in dietary steatohepatitis in mice. Hepatology 2003, 38(1):123-132

35. Kris-Etherton PM, Harris WS, Appel LJ: Fish consumption, fish oil, omega-3 fatty acids, and cardiovascular disease. Circulation 2002, 106(21):2747-2757.

36. Diabetes Atherosclerosis Intervention Study Investigators: Effect of fenofibrate on progression of coronary-artery disease in type 2 diabetes: the Diabetes Atherosclerosis Intervention Study, a randomised study. Lancet 2001, 357(9260):905-910.

37. Keech A, Simes RJ, Barter P, Best J, Scott R, Taskinen MR, Forder P, Pillai A, Davis T, Glasziou P, Drury P, Kesäniemi YA, Sullivan D, Hunt D, Colman P, d'Emden M, Whiting M, Ehnholm C, Laakso M, FIELD study investigators: Effects of long-term fenofibrate therapy on cardiovascular events in 9795 people with type 2 diabetes mellitus (the FIELD study): randomised controlled trial. Lancet 2005, 366(9500):1849-1861.

38. Ginsberg HN, Elam MB, Lovato LC, Crouse JR 3rd, Leiter LA, Linz P, Friedewald WT, Buse JB, Gerstein HC, Probstfield J, Grimm RH, Ismail-Beigi F, Bigger JT, Goff DC Jr, Cushman WC, Simons-Morton DG, Byington RP, ACCORD Study Group: Effects of combination lipid therapy in type 2 diabetes mellitus. N Engl J Med 2010, 362(17):1563-1574.

39. Davis TM, Ting R, Best JD, Donoghoe MW, Drury PL, Sullivan DR, Jenkins AJ, O'Connel RL, Whiting MJ, Glasziou PP, Simes RJ, Kesäniemi YA, Gebski VJ, Scott RS, Keech AC, Fenofibrate Intervention and Event Lowering in Diabetes Study investigators: Effects of fenofibrate on renal function in patients with type 2 diabetes mellitus: the Fenofibrate Intervention and Event Lowering in Diabetes (FIELD) Study. Diabetologia 2011, 54(2):280-290.
40. Forsblom C, Hiukka A, Leinonen ES, Sundvall J, Groop PH, Taskinen MR: Effects of long-term fenofibrate treatment on markers of renal function in type 2 diabetes: the FIELD Helsinki substudy. Diabetes Care 2010, 33(2):215-220

41. Hottelart C, El Esper N, Rose F, Achard JM, Fournier A: Fenofibrate increases creatininemia by increasing metabolic production of creatinine. Nephron 2002, 92(3):536-541.

42. Berger J, Leibowitz MD, Doebber TW, Elbrecht A, Zhang B, Zhou G, Biswas C, Cullinan CA, Hayes NS, Li Y, Tanen M, Ventre J, Wu MS, Berger GD, Mosley R, Marquis R, Santini C, Sahoo SP, Tolman RL, Smith RG, Moller DE: Novel peroxisome proliferator-activated receptor (PPAR) gamma and PPARdelta ligands produce distinct biological effects. J Biol Chem 1999, 274(10):6718-6725.

43. Ngala RA, Stocker CJ, Roy AG, Hislop D, Wargent E, Bell R, Hassall DG, Harling JD, Billin AN, Willson TM, Arch JR, Cawthorne MA: A new, highly selective marine peroxisome proliferator-activated receptor delta agonist increases responsiveness to thermogenic stimuli and glucose uptake in skeletal muscle in obese mice. Diab Obes Metab 2011, 13(5):455-464.

44. Burkart EM, Sambandam N, Han X, Gross RW, Courtois M, Gierasch CM, Shoghi K, Welch MJ, Kelly DP: Nuclear receptors PPAR beta/delta and PPAR alpha direct distinct metabolic regulatory programs in the mouse heart. J Clin Invest 2007, 117(12):3930-3939.

45. Yu BC, Chang CK, Ou HY, Cheng KC, Cheng JT: Decrease of peroxisome proliferator-activated receptor delta expression in cardiomyopathy of streptozotocin-induced diabetic rats. Cardiovasc Res 2008, 80(1):78-87.

46. Lim H, Dey SK: PPAR delta functions as a prostacyclin receptor in blastocyst implantation. Trends Endocrinol Metab 2000, 11(4):137-142

47. Michalik L, Desvergne B, Wahli W: Peroxisome-proliferator-activated receptors and cancers: complex stories. Nat Rev Cancer 2004, 4(1):61-70.

48. Henke BR: Peroxisome proliferator-activated receptor alpha/gamma dual agonists for the treatment of type 2 diabetes. J Med Chem 2004, 47(17):4118-4127.

49. Kintscher U, Law RE: PPARymediated insulin sensitization: the importance of fat versus muscle. Am J Physiol Endocrinol Metab 2005, 288(2):E287-E291

50. Marx N, Bourcier T, Sukhova GK, Libby P, Plutzky J: PPARgamma activation in human endothelial cells increases plasminogen activator inhibitor type-1 expression: PPARgamma as a potential mediator in vascular disease. Arterioscler Thromb Vasc Biol 1999, 19(3):546-551.

51. Panigrahy D, Huang S, Kieran MW, Kaipainen A: PPARgamma as a therapeutic target for tumor angiogenesis and metastasis. Cancer Biol Ther 2005, 4(7):687-693.

52. Sporn MB, Suh N, Mangelsdorf DJ: Prospects for prevention and treatment of cancer with selective PPARy modulators (SPARMs). Trends Mol Med 2001, 7(9):395-400

53. Trombetta A, Maggiora M, Martinasso G, Cotogni P, Canuto RA, Muzio G: Arachidonic and docosahexaenoic acids reduce the growth of A549 human lung-tumor cells increasing lipid peroxidation and PPARs. Chem Biol Interact 2007, 165(3):239-250.

54. Edwards IJ, Berquin IM, Sun H, O'Flaherty JT, Daniel LW, Thomas MJ, Rudel $L L$, Wykle RL, Chen YQ: Differential effects of delivery of omega-3 fatty acids to human cancer cells by low-density lipoproteins versus albumin. Clin Cancer Res 2004, 10(24):8275-8283.

55. Sun $\mathrm{H}$, Berquin IM, Edwards IJ: Omega-3 polyunsaturated fatty acids regulate syndecan-1 expression in human breast cancer cells. Cancer Res 2005, 65(10):4442-4447.

56. Sun H, Berquin IM, Owens RT, O'Flaherty JT, Edwards IJ: Peroxisome proliferator-activated receptor $\gamma$-mediated up-regulation of syndecan-1 by $n-3$ fatty acids promotes apoptosis of human breast cancer cells. Cancer Res 2008, 68(8):2912-2919.

57. Yang ZH, Miyahara H, Iwasaki Y, Takeo J, Katayama M: Dietary supplementation with long-chain monounsaturated fatty acids attenuates obesity-related metabolic dysfunction and increases expression of PPAR gamma in adipose tissue in type 2 diabetic KK-Ay mice. Nutr Metab (Lond) 2013, 10(1):16.

58. Mishra A, Chaudhary A, Sethi S: Oxidized omega-3 fatty acids inhibit NF-KB activation via a PPARa-dependent pathway. Arterioscler Thromb Vasc Biol 2004, 24(9):1621-1627.

59. Suchanek KM, May FJ, Robinson JA, Lee WJ, Holman NA, Monteith GR, Roberts-Thomson SJ: Peroxisome proliferator-activated receptor alpha in the human breast cancer cell lines MCF-7 and MDA-MB-231. Mol Carcinog 2002, 34(4):165-171. 
60. Heim M, Johnson J, Boess F, Bendik I, Weber P, Hunziker W, Fluhmann B: Phytanic acid, a natural peroxisome proliferator-activated receptor (PPAR) agonist, regulates glucose metabolism in rat primary hepatocytes. FASEB J 2002, 16(7):718-720.

61. Elstner E, Müller C, Koshizuka K, Williamson EA, Park D, Asou H, Shintaku P Said JW, Heber D, Koeffler HP: Ligands for peroxisome proliferatoractivated receptor $\gamma$ and retinoic acid receptor inhibit growth and induce apoptosis of human breast cancer cells in vitro and in BNX mice. Proc Natl Acad Sci U S A 1998, 95(15):8806-8811.

62. Tan MH: Current treatment of insulin resistance in type 2 diabetes mellitus. Int J Clin Pract Supp/ 2000, 113:54-62.

63. Deeg MA, Tan MH: Pioglitazone versus rosiglitazone: effects on lipids, lipoproteins, and apolipoproteins in head-to-head randomized clinical studies. PPAR Res 2008, 2008:520465.

64. Krishnaswami A, Ravi-Kumar S, Lewis JM: Thiazolidinediones: a 2010 perspective. Perm J 2010, 14(3):64-72.

65. Chang F, Jaber LA, Berlie HD, O'Connell MB: Evolution of peroxisome proliferator-activated receptor agonists. Ann Pharmacother 2007, 41(6):973-983.

66. Aronoff S, Rosenblatt S, Braithwaite S, Egan JW, Mathisen AL, Schneider RL: Pioglitazone hydrochloride monotherapy improves glycemic control in the treatment of patients with type 2 diabetes: a 6-month randomized placebo-controlled dose-response study. The Pioglitazone 001 Study Group. Diabetes Care 2000, 23(11):1605-1611.

67. Raskin P, Rappaport EB, Cole ST, Yan Y, Patwardhan R, Freed MI: Rosiglitazone short-term monotherapy lowers fasting and post-prandial glucose in patients with type II diabetes. Diabetologia 2000, 43(3):278-284

68. Dormandy J, Bhattacharya M, Van Troostenburg de Bruyn AR: Safety and tolerability of pioglitazone in high-risk patients with type 2 diabetes: an overview of data from PROactive. Drug Saf 2009, 32(3):187-202.

69. Nissen SE, Wolski K: Effect of rosiglitazone on the risk of myocardial infarction and death from cardiovascular causes. N Engl J Med 2007, 356(24):2457-2471.

70. Peters Harmel AL, Kendall DM, Buse JB, Boyle PJ, Marchetti A, Lau H: Impact of adjunctive thiazolidinedione therapy on blood lipid levels and glycemic control in patients with type 2 diabetes. Curr Med Res Opin 2004, 20(2):215-223.

71. Diamant $M$, Heine $R J$ : Thiazolidinediones in type 2 diabetes mellitus: current clinical evidence. Drugs 2003, 63(13):1373-1405.

72. Caballero A, Saouaf R, Lim SC, Hamdy O, Abou-Elenin K, O'Connor C, LoGerfo FW, Horton ES, Veves A: The effects of troglitazone, an insulin-sensitizing agent, on the endothelial function in early and late type 2 diabetes: a placebo-controlled randomized clinical trial. Metabolism 2003, 52(2):173-180.

73. Bagi Z, Koller A, Kaley G: PPARgamma activation, by reducing oxidative stress, increases NO bioavailability in coronary arterioles of mice with Type 2 diabetes. Am J Physiol Heart Circ Physiol 2004, 286(2):H742-H748.

74. Marlow LA, Reynolds LA, Cleland AS, Cooper SJ, Gumz ML, Kurakata S, Fujiwara K, Zhang Y, Sebo T, Grant C, Mclver B, Wadsworth JT, Radisky DC, Smallridge RC, Copland JA: Reactivation of suppressed RhoB is a critical step for the inhibition of anaplastic thyroid cancer growth. Cancer Res 2009, 69(4):1536-1544.

75. Tolman KG: The safety of thiazolidinediones. Expert Opin Drug Saf 2011, 10(3):419-428.

76. Rubenstrunk A, Hanf R, Hum DW, Fruchart JC, Staels B: Safety issues and prospects for future generations of PPAR modulators. Biochim Biophys Acta 2007, 1771(8):1065-1081.

77. Carmona MC, Louche K, Lefebvre B, Pilon A, Hennuyer N, Audinot-Bouchez V, Fievet C, Torpier G, Formstecher P, Renard P, Lefebvre P, Dacquet C, Staels B, Casteilla L, Pénicaud L, Consortium of the French Ministry of Research and Technology: S 26948: a new specific peroxisome proliferator activated receptor gamma modulator with potent antidiabetes and antiatherogenic effects. Diabetes 2007, 56(11):2797-2808.

78. Dunn FL, Higgins LS, Fredrickson J, DePaoli AM: Selective modulation of PPARgamma activity can lower plasma glucose without typical thiazolidinedione side-effects in patients with Type 2 diabetes. J Diabetes Complicat 2011, 25(3):151-158.

79. Grommes C, Landreth GE, Heneka MT: Antineoplastic effects of peroxisome proliferator-activated receptor gamma agonists. Lancet Oncol 2004, 5(7):419-429.
80. Long GG, Reynolds VL, Lopez-Martinez A, Ryan TE, White SL, Eldridge SR: Urothelial carcinogenesis in the urinary bladder of rats treated with naveglitazar, a gamma-dominant PPAR alpha/gamma agonist: lack of evidence for urolithiasis as an inciting event. Toxicol Pathol 2008, 36(2):218-231.

81. Wilding JP, Gause-Nilsson I, Persson A: Tesaglitazar, as add-on therapy to sulphonylurea, dose-dependently improves glucose and lipid abnormalities in patients with type 2 diabetes. Diab Vasc Dis Res 2007, 4(3):194-203.

82. Nissen SE, Wolski K, Topol EJ: Effect of muraglitazar on death and major adverse cardiovascular events in patients with type 2 diabetes mellitus. JAMA 2005, 294(20):2581-2586.

83. Henry RR, Lincoff AM, Mudaliar S, Rabbia M, Chognot C, Herz M: Effect of the dual peroxisome proliferator-activated receptor-alpha/gamma agonist aleglitazar on risk of cardiovascular disease in patients with type 2 diabetes (SYNCHRONY): a phase II, randomised, dose-ranging study. Lancet 2009, 374(9684):126-135.

doi:10.1186/1475-2891-13-17

Cite this article as: Grygiel-Górniak: Peroxisome proliferator-activated receptors and their ligands: nutritional and clinical implications - a review. Nutrition Journal 2014 13:17.

\section{Submit your next manuscript to BioMed Central and take full advantage of:}

- Convenient online submission

- Thorough peer review

- No space constraints or color figure charges

- Immediate publication on acceptance

- Inclusion in PubMed, CAS, Scopus and Google Scholar

- Research which is freely available for redistribution

Submit your manuscript at www.biomedcentral.com/submit
C BioMed Central 